\title{
Analisis Kondisi Fisik dan Teknik Dasar Pemain Sepak Bola Klub Mahardhika Kecamatan Belik Kabupaten Pemalang
}

\author{
Hendry Bagus Presetyo ${ }^{1}$, Dani Slamet Pratama ${ }^{2}$, Bertika Kusuma Prastiwi ${ }^{3}$ \\ ${ }^{123}$ Progam studi Pendidikan Jasmani Kesehatan dan Rekreasi Fakultas Pendidikan Ilmu Pengetahuan Sosial, \\ Kesehatan dan Rekreasi Universitas PGRI Semarang J1. Dr. Cipto Semarang, Jawa Tengah, \\ Indonesia \\ .E-mail : hendrybagusp03@gmail.com¹
}

Received: 21 anuari 2021; Revised: 14 Agustus 2021; Accepted: 20 Desember 2021

\begin{abstract}
The research method used is a survey, data collection techniques using tests and measurements with the Battery Test system. The data analysis technique used descriptive statistics. This type of research is descriptive quantitative. The population in this study were $20 \mathrm{U}-18$ mahardika soccer players. The instruments used in the physical condition test are: Leg and dynamometer, MFT, Standing Board Jump, 50 meter Sprint, Sit and Reach, Agility T-test, squat thrust, strock stand, shooting, catch the ruler. As for the basic technical tests, the tests used are: passing, dribbling and shooting.

The results of descriptive statistics of the physical condition of Mahardika club soccer players get 5\% (1 person) with the very good category. $35 \%$ ( 7 people) in the good category, 30\% (6 people) in the moderate category, $20 \%$ (4 people) with the poor category and $10 \%$ ( 2 people) with the very poor category. In the basic engineering research results obtained 5\% (1 person) in the very good category, $45 \%$ (9 people) in the good category, 15\% (3 people) in the moderate category, $30 \%$ (6 people) in the poor category and $5 \%$ ( 1 person) in the very poor category.

Based on the results of the study, it can be concluded that the physical conditions and basic techniques of Mahardika club soccer players fall into the moderate category. Suggestions given by researchers: 1) The trainer can make a better and more effective exercise program to improve physical condition and basic techniques. 2) Athletes are expected to be more serious in maintaining and improving basic physical and technical conditions.
\end{abstract}

Keywords: Physical Condition, Basic Technique, Football

\begin{abstract}
Abstrak
Metode penelitian yang digunakan adalah survey, teknik pengambilan data menggunakan tes dan pengukuran dengan sistem Battery Test. Teknik analisis data menggunakan statistik deskriptif. Jenis penelitian ini adalah deskriptif kuantitatif. Populasi pada penelitian ini adalah pemain sepak bola mahardika U-18 yang berjumlah 20 pemain. Instrument yang digunakan dalam tes kondisi fisik adalah: Leg and dynamometer, MFT, Standing Board Jump, Sprint 50 meter, Sit and Reach, Agility T-test, squat thrust, strock stand, shooting, Tangkap penggaris. Sedangkan untuk tes teknik dasar, tes yang digunakan adalah: passing, dribbling dan shooting.
\end{abstract}

Hasil statistik deskriptif kondisi fisik pemain sepak bola klub mahardika memperoleh 5\% (1 orang) dengan kategori sangat baik. 35\% (7 orang) dengan kategori baik, 30\% (6 orang) dengan kategori sedang, 20\% (4 orang) dengan kategori kurang dan 10\% (2 orang) dengan kategori sangat kurang. Pada hasil penelitian teknik dasar memperoleh 5\% (1 orang) dalam kategori sangat baik, 45\% (9 orang) dalam kategori baik, 15\% (3 orang) dalam kategori sedang, 30\% (6 orang) dalam kategori kurang dan 5\% (1 orang) dalam kategori sangat kurang.

Berdasarksn hasil penelitian dapat disimpulkan bahwa kondisi fisik dan teknik dasar pemain sepak bola klub mahardika masuk dalam kategori sedang. Saran yang diberikan peneliti: 1) Pelatih dapat membuat program latihan 
yang lebih baik dan efektif untuk meningkatkan kondisi fisik dan teknik dasar. 2) Untuk atlet diharapkan lebih bersungguh-sungguh lagi dalam menjaga maupun meningkatkan kondisi fisik dan teknik dasar.

Kata Kunci : Kondisi Fisik, Teknik Dasar, Sepak Bola

\section{PENDAHULUAN}

Olahraga merupakan suatu kegiatan fisik yang bertujuan untuk menjaga dan meningkatkan kebugaran tubuh seseorang. Dari sudut pandang Ilmu Faal Olahraga, Olahraga adalah serangkaian gerak raga yang teratur dan terencana yang dilakukan orang dengan sadar untuk meningkatkan kemampuan fungsionalnya, sesuai dengan tujuannya melakukan olahraga (Prativi, G.O.,Soegiyanto dan Sutardji, 2013: 33).

Sepak bola tidak hanya untuk berolahraga menjaga kebugaran saja, tetapi sepak bola merupakan salah satu olahraga yang dapat mencerdaskan anak bangsa dengan meraih prestasi setinggitingginya. Adapun faktor yang dapat di kembangkan untuk mendapatkan prestasi yang lebih baik yaitu dengan mempunyai kondisi fisik dan keterampilan teknik dasar yang baik.

Menurut Eri Pratiknyo Dwikusworo, dalam (Febriatmoko, Junaidi and Nugroho, 2013:38) Kondisi fisik adalah suatu kesatuan komponen fisik yang dimiliki seseorang, kondisi fisik merupakan prasyarat yang harus dimiliki seorang atlet dalam meningkatkan dan mengembangkan prestasi olahraga yang optimal, sehingga segenap kondisi fisiknya harus dikembangkan dan ditingkatkan sesuai dengan ciri, karakteristik dan kebutuhan masing-masing cabang olahraga. Artinya tuntutan fisik dalam sepak bola yaitu pemain mampu bermain selama 2 babak ( 2 x 45 menit) tanpa mengalami penurunan kondisi fisik yang drastis. Sehingga pemain mampu bertahan pada saat terjadinya bodi kontak atau benturan keras dengan pemain lawan.

Cabang olahraga sepak bola merupakan olahraga yang membutuhkan kombinasi antara teknik, kondisi fisik dan juga mental. Menurut Agustina RS (2020: 28) teknik dasar merupakan suatu keterampilan individu tiap-tiap pemain untuk melakukan pergerakan baik dengan bola maupun tanpa bola. Salah satu faktor yang penting untuk meraih prestasi dalam sepak bola adalah memiliki kemampuan teknik dasar yang baik. Adapun teknik dasar dalam olahraga sepak bola adalah passing, dribbling, dan shooting. Oleh karena itu, keterampilan teknik dasar dibutuhkan dalam kerja sama antar pemain untuk mencapai tujuan permainan dan menjadikan timnya sebagai pemenang dalam suatu pertandingan. Kondisi fisik dan teknik dasar yang baik harus dimiliki oleh pemain untuk menghadapi kompetisi-kompetisi sepak bola yang akan datang. Klub Mahardika merupakan salah satu Klub yang dimiliki oleh desa sikasur untuk bersaing dalam liga 2 di kabupaten pemalang. Klub Mahardika didirikan sejak tahun 2018, namun sepanjang perjalanan karir Klub tersebut belum bisa memberikan prestasi terbaik.

Berdasarkan observasi yang dilakukan pada tanggal 8 Juli 2020 dalam pertandingan persahabatan antara Mahardika vs Persemi dan observasi langsung dilapangan dengan pelatih Wildan bahwa pemain Mahardika FC masih belum maksimal dalam menguasai permainan serta peneliti melihat kondisi fisik dan teknik dasar masih jauh dari yang diharapkan. Pada babak pertama menit-menit awal pemain Mahardika bermain dengan tempo cepat, namun pada 20 menit terakhir tepatnya menit 70-90 pemain mulai kehabisan tenaga, konsentrasi pemain buyar. Saat pemain melakukan passing $60 \%$ bola lebih banyak di intersep lawan karena passing yang tidak akurat, tidak sampai bahkan salah passing. Controlling bola yang kurang baik serta sering kehilangan bola ketika melakukan dribbling, dari 90 menit permainan hanya 5 kali pemain melakukan tembakan yang mengarah ke gawang, pemain tidak 
bisa mempertahankan tempo permainan seperti awal babak pertama. Kondisi seperti inilah yang bisa dimanfaatkan oleh pemain lawan untuk bisa mencetak gol.

Pada pertandingan persahabatan antara Persemi vs Mahardika dimenangkan oleh Persemi dengan Skor 2-1. Kondisi fisik, teknik dan mental bermain akan mempengaruhi permainan di dalam lapangan, kurangnya data tentang kondisi fisik dan teknik dasar yang dimiliki pemain Mahardika menjadi kendala dalam menyusun program latihan yang tepat. Prestasi akan dapat diraih dengan baik ketika pelatih mempersiapkan tim dengan matang dari kondisi fisik, teknik hingga mental bermain. Usaha dalam meraih prestasi bisa di mulai dengan mengetahui data kondisi fisik dan teknik dasar sebelum melakukan pembenahan program latihan kondisi fisik dan teknik dasar yang dibutuhkan untuk meningkatkan kemampuan yang sudah dimiliki setiap pemain. Pemain Mahardika belum pernah melakukan tes kondisi fisik dan teknik dasar pemain selama mengikuti liga 2 kabupaten pemalang. Berdasarkan permasalahan diatas, maka peneliti tertarik untuk melakukan penelitian ini yang berjudul "Analisis Kondisi Fisik dan Teknik Dasar Pemain Sepak Bola Klub Mahardika Kecamatan Belik Kabupaten Pemalang”.

\section{METODE}

Metode penelitian yang digunakan adalah survey, teknik pengambilan data menggunakan tes dan pengukuran dengan sistem Battery Test. Teknik analisis data menggunakan statistik deskriptif. Jenis penelitian ini adalah deskriptif kuantitatif. Populasi pada penelitian ini adalah pemain sepak bola mahardika U-18 yang berjumlah 20 pemain. Instrument yang digunakan dalam tes kondisi fisik adalah: Leg and dynamometer, MFT, Standing Board Jump, Sprint 50 meter, Sit and Reach, Agility T-test, squat thrust, strock stand, shooting, Tangkap penggaris. Sedangkan untuk tes teknik dasar, tes yang digunakan adalah: passing, dribbling dan shooting.

\section{HASIL DAN PEMBAHASAN}

\section{Kondisi Fisik}

\section{a. Hasil Tes Kekuatan}

Hasil tes kekuatan untuk mengukur kekuatan otot tungkai kaki dengan menggunakan tes leg dynamometer, maka ditampilkan dengan tabel sebagai berikut :

Tabel 4. 1 Distribusi frekuensi kekuatan otot tungkai kaki

\begin{tabular}{|l|l|l|l|l|}
\hline \multirow{2}{*}{ No. } & \multirow{3}{*}{ Norma (S) } & Frekuensi & \\
\cline { 3 - 4 } & & $\begin{array}{l}\text { Absolut } \\
\text { (FA) }\end{array}$ & Relatif (\%) & \\
\hline 1 & SD -52.00 & 1 & $5 \%$ & Kurang \\
\hline 2 & $52.50-76$ & 9 & $45 \%$ & Cukup \\
\hline 3 & $76.50-112.00$ & 10 & $50 \%$ & Sedang \\
\hline 4 & $112.50-153.00$ & 0 & $0 \%$ & Bagus \\
\hline 5 & $153.50-$ ketas & 0 & $0 \%$ & Bagus Sekali \\
\hline & Jumlah & 20 & $100 \%$ & \\
\hline
\end{tabular}

Berdasarkan tabel diatas dijelaskan bahwa, kekuatan otot tungkai kaki pemain mahardika dengan kategori baik sekali tidak ada. Kategori bagus tidak ada.kategori sedang ada 10 orang dengan rentangan nilai $76.50-112.00 \mathrm{~kg}$. Kategori cukup ada 9 orang dengan rentangan nilai $52.50-$ $76 \mathrm{~kg}$. Kategori kurang ada 1 orang dengan rentangan nilai SD - 52.00kg.

\section{b. Hasil Tes Daya Tahan}


Hasil tes daya tahan (VO2MAX) dengan menggunakan Test multistage fitness, maka ditampilkan dengan tabel sebagai berikut:

Tabel 4. 2 Distribusi Frekuensi Daya Tahan (VO2MAX)

\begin{tabular}{|c|c|c|c|c|}
\hline \multirow[b]{2}{*}{ No } & \multirow[b]{2}{*}{ Norma } & \multicolumn{2}{|c|}{ Frekuensi } & \multirow[b]{2}{*}{ Kategori } \\
\hline & & $\begin{array}{l}\text { Absolut } \\
\text { (FA) }\end{array}$ & Relatif (\%) & \\
\hline 1 & $<35.0$ & 1 & $5 \%$ & Sangat Kurang \\
\hline 2 & $35.0-38.0$ & 2 & $10 \%$ & Kurang \\
\hline 3 & $38.4-45.1$ & 10 & $50 \%$ & Cukup \\
\hline 4 & $45.2-50.9$ & 7 & $35 \%$ & Baik \\
\hline 5 & $51.0>$ & 0 & $0 \%$ & Sangat Baik \\
\hline & Jumlah & 20 & $100 \%$ & \\
\hline
\end{tabular}

Berdasarkan tabel diatas dijelaskan bahwa, daya tahan pemain Mahardika dengan kategori sangat baik tidak ada. Kategori baik ada 7 orang dengan rentangan nilai 45.2 - 50.9. kategori cukup ada 10 orang dengan rentangan nilai 38.4 - 45.1. Kategori kurang ada 2 orang dengan rentangan nilai 35.0 - 38.0. Kategori sangat kurang ada 1 orang dengan rentangan nilai <35.0.

\section{c. Hasil Tes Power}

Hasil tes daya eksplosif/ power dengan menggunakan Tes Standing Board Jump, maka ditampilkan dengan tabel sebagai berikut:

Tabel 4. 3 Distribusi Frekuensi Daya Eksplosif/ Power

\begin{tabular}{|c|c|c|c|c|}
\hline \multirow[b]{2}{*}{ No. } & \multirow[b]{2}{*}{ Norma (Cm) } & \multicolumn{2}{|c|}{ Frekuensi } & \multirow[b]{2}{*}{ Kategori } \\
\hline & & $\begin{array}{l}\text { Absolut } \\
\text { (FA) }\end{array}$ & Relatif (\%) & \\
\hline 1 & $211-220$ & 3 & $15 \%$ & Kurang \\
\hline 2 & $221-230$ & 4 & $20 \%$ & Sedang \\
\hline 3 & $231-240$ & 11 & $55 \%$ & Cukup \\
\hline 4 & $241-250$ & 2 & $10 \%$ & Baik \\
\hline 5 & $>250$ & 0 & $0 \%$ & Baik Sekali \\
\hline \multicolumn{2}{|c|}{ Jumlah } & 20 & $100 \%$ & \\
\hline
\end{tabular}

Berdasarkan tabel diatas dijelaskan bahwa, daya eksplosif / power pemain Mahardika dengan kategori baik sekali tidak ada. Kategori baik ada 2 orangdengan rentangan nilai 241-250 cm. kategori cukup ada 11 orang dengan rentangan nilai $231-240 \mathrm{~cm}$. Kategori sedang ada 4 orang dengan rentangan nilai $221-230 \mathrm{~cm}$. Kategori kurang ada 3 orang dengan rentangan nilai 211$220 \mathrm{~cm}$.

\section{d. Hasil tes kecepatan}

Hasil tes kecepatan / speed dengan menggunakan Tes Sprint 50 meter, maka ditampilkan dengan tabel sebagai berikut:

Tabel 4. 4 Distribusi Frekuensi Kecepatan

\begin{tabular}{|c|c|c|c|c|}
\hline \multirow[b]{2}{*}{ No } & \multirow[b]{2}{*}{ Norma } & \multicolumn{2}{|c|}{ Frekuensi } & \multirow[b]{2}{*}{ Kategori } \\
\hline & & $\begin{array}{l}\text { Absolut } \\
\text { (FA) }\end{array}$ & Relatif (\%) & \\
\hline 1 & $10.4>$ & 0 & $0 \%$ & Kurang Sekali \\
\hline 2 & $8.8-10.3$ & 0 & $0 \%$ & Kurang \\
\hline 3 & $7.7-8.7$ & 5 & $25 \%$ & Cukup \\
\hline 4 & $6.8-7.6$ & 13 & $65 \%$ & Baik \\
\hline 5 & S.D - 6.7 & 2 & $10 \%$ & Baik Sekali \\
\hline
\end{tabular}




\begin{tabular}{|l|l|l}
\hline Jumlah & 20 & $100 \%$ \\
\hline
\end{tabular}

Berdasarkan tabel diatas dijelaskan bahwa, kecepatan / speed pemain Mahardika dengan kategori baik sekali ada 2 orang dengan rentangan nilai S.D - 6.7 detik. Kategori baik ada 13 orang dengan rentangan nilai 6.8 - 7.6 detik. kategori cukup ada 5 orang dengan rentangan nilai 7.7 - 8.7 detik. Kategori kurang tidak ada.Kategori kurang sekali tidak ada.

\section{e. Hasil tes kelentukan}

Hasil tes kelentukan / flexsibility dengan menggunakan Test Sit and Reach, maka ditampilkan dengan tabel sebagai berikut:

Tabel 4. 5 Distribusi Frekuensi Kelentukan

\begin{tabular}{|l|l|l|l|l|}
\hline \multirow{2}{*}{ No } & \multirow{2}{*}{ Norma } & Frekuensi & \multirow{2}{*}{ Kategori } \\
\cline { 3 - 4 } & & Absolut (FA) & Relatif(\%) & \\
\hline 1 & $<12,0$ & 1 & $5 \%$ & Kurang Sekali \\
\hline 2 & $12,5-14,0$ & 5 & $25 \%$ & Kurang \\
\hline 3 & $14,5-16,5$ & 5 & $25 \%$ & Cukup \\
\hline 4 & $17,0-19,0$ & 9 & $45 \%$ & Baik \\
\hline 5 & $>19,5$ & 0 & $0 \%$ & Baik Sekali \\
\hline \multicolumn{2}{|l}{ Jumlah } & 20 & $100 \%$ & \\
\hline
\end{tabular}

Berdasarkan tabel diatas dijelaskan bahwa, kelentukan / flexsibility pemain Mahardika dengan kategori baik sekali tidak ada. Kategori baik ada 9 orang dengan rentangan nilai 17,0 - 19,0 cm. kategori cukup ada 5 orang dengan rentangan nilai $14,5-16,5 \mathrm{~cm}$. Kategori kurang ada 5 orang dengan rentangan nilai 12,5 -14,0 cm.Kategori kurang sekali ada 1 orang dengan rentangan nilai $<12,0 \mathrm{~cm}$.

\section{f. Hasil tes kelincahan}

Hasil tes daya kelincahan / agility dengan menggunakan Agility T-Test, maka ditampilkan dengan tabel sebagai berikut:

Tabel 4. 6 Distribusi Frekuensi Kelincahan

\begin{tabular}{|l|l|l|l|l|}
\hline \multirow{2}{*}{ No. } & \multirow{3}{*}{ Norma } & Frekuensi & \multirow{2}{*}{ Kategori } \\
\cline { 3 - 4 } & & $\begin{array}{l}\text { Absolut } \\
(\mathrm{FA})\end{array}$ & Relatif $(\%)$ & \\
\hline 1 & $<9,5$ & 7 & $35 \%$ & Excellent \\
\hline 2 & $9,5-10,5$ & 11 & $55 \%$ & Good \\
\hline 3 & $10,5-11,5$ & 1 & $5 \%$ & Average \\
\hline 4 & $>11,5$ & 1 & $5 \%$ & Poor \\
\hline \multicolumn{2}{|l|}{ Jumlah } & 20 & $100 \%$ & \\
\hline
\end{tabular}

Berdasarkan tabel diatas dijelaskan bahwa, kelincahan /agility pemain Mahardika dengan kategori Excellent ada 7 orang dengan rentangan nilai <9,5 detik. Kategori Good ada 11 orang dengan rentangan,nilai 9,5 - 10,5 detik. kategori Average ada 1 orang dengan rentangan nilai 10,5 - 11,5 detik. Kategori poor ada 1 orang dengan rentangan nilai >11,5 detik.

\section{g. Hasil Tes Koordinasi}

Hasil tes koordinasi / coordination dengan menggunakan Tes Squat Thrust,maka ditampilkan dengan tabel sebagai berikut:

Tabel 4. 7 Distribusi Frekuensi Koordinasi Pemain Sepak Bola Klub Mahardika

\begin{tabular}{|l|l|l|l|l|}
\hline \multirow{2}{*}{ No } & \multirow{3}{*}{ Norma } & \multicolumn{2}{|l|}{ Frekuensi } & \multirow{2}{*}{ Kategori } \\
\cline { 3 - 4 } & $\begin{array}{l}\text { Absolut } \\
(\mathrm{FA})\end{array}$ & $\begin{array}{l}\text { Relatif } \\
(\%)\end{array}$ & \\
\hline
\end{tabular}




\begin{tabular}{|l|l|l|l|l|}
1 & $0-15$ & 0 & $0 \%$ & Kurang Sekali \\
\hline 2 & $16-25$ & 3 & $15 \%$ & Kurang \\
\hline 3 & $26-35$ & 10 & $50 \%$ & Cukup \\
\hline 4 & $36-45$ & 7 & $35 \%$ & Baik \\
\hline 5 & $>45$ & 0 & $0 \%$ & Baik Sekali \\
\hline Jumlah & 20 & $100 \%$ & \\
\hline
\end{tabular}

Berdasarkan tabel diatas dijelaskan bahwa, koordinasi / coordination pemain mahardika dengan kategori baik sekali tidak ada. Kategori baik ada 7 orang dengan rentangan nilai $36-45$. Kategori cukup ada 10 orang dengan rentangan nilai $26-35$. Kategori kurang ada 3 orang dengan rentangan nilai $16-25$. Kategori kurang sekali tidak ada.

\section{h. Hasil tes keseimbangan}

Hasil tes keseimbangan / balance dengan menggunakan Tes Strock Stand, maka ditampilkan dengan tabel sebagai berikut:

Tabel 4. 8 Distribusi Frekuensi Keseimbangan

\begin{tabular}{|l|l|l|l|l|}
\hline \multirow{2}{*}{ No } & \multirow{2}{*}{ Norma } & Frekuensi & \multirow{2}{*}{ Kategori } \\
\cline { 3 - 5 } & & Absolut (FA) & Relatif(\%) & \\
\hline 1 & $>50$ & 0 & $0 \%$ & Exellent \\
\hline 2 & $40-50$ & 7 & $35 \%$ & Good \\
\hline 3 & $25-39$ & 9 & $45 \%$ & Average \\
\hline 4 & $10-24$ & 4 & $20 \%$ & Fair \\
\hline 5 & $<10$ & 0 & $0 \%$ & Poor \\
\hline Jumlah & 20 & $100 \%$ & \\
\hline
\end{tabular}

Berdasarkan tabel diatas dijelaskan bahwa, keseimbangan / balance pemain MAHARDIKA dengan kategori Exellent tidak ada. Kategori Good ada 7 orang dengan rentangan nilai 40 - 50 detik. Kategori Average ada 9 orang dengan rentangan 25 - 39 detik. Kategori Fair ada 4 orang dengan rentangan nilai $10-24$ detik. Kategori Poor tidak ada.

\section{i. Hasil Tes Ketepatan}

Hasil tes ketepatan / accuricy dengan menggunakan Tes Shooting, maka ditampilkan dengan tabel sebagai berikut:

Tabel 4. 9 Distribusi Frekuensi Ketepatan Pemain Sepak Bola Klub Mahardika

\begin{tabular}{|c|c|c|c|c|}
\hline \multirow[b]{2}{*}{ No } & \multirow[b]{2}{*}{ Point } & \multicolumn{2}{|c|}{ Frekuensi } & \multirow[b]{2}{*}{ Kategori } \\
\hline & & $\begin{array}{l}\text { Absolut } \\
\text { (FA) }\end{array}$ & $\begin{array}{l}\text { Relatif } \\
(\%)\end{array}$ & \\
\hline 1 & $>17$ & 0 & $0 \%$ & Sangat Baik \\
\hline 2 & $12-16$ & 8 & $40 \%$ & Baik \\
\hline 3 & $8-11$ & 10 & $50 \%$ & Sedang \\
\hline 4 & $4-7$ & 2 & $10 \%$ & Kurang \\
\hline 5 & $<3$ & 0 & $0 \%$ & Sangat Kurang \\
\hline \multicolumn{2}{|c|}{ Jumlah } & 20 & $100 \%$ & \\
\hline
\end{tabular}

Berdasarkan tabel diatas dijelaskan bahwa, ketepatan / accuricy pemain Mahardika dengan kategori sangat baik tidak ada. Kategori baik ada 8 orang dengan rentangan nilai 12-16. Kategori sedang ada 10 orang dengan rentangan nilai 8-11. Kategori kurang ada 2 orang dengan rentangan nilai 4-7. Kategori sangat kurang tidak ada.

\section{j. Hasil tes reaksi}

Hasil tes reaksi / reaction dengan menggunakan Tes Tangkap Penggaris, maka ditampilkan dengan tabel sebagai berikut: 
Tabel 4. 10 Distribusi Frekuensi Reaksi

\begin{tabular}{|l|l|l|l|l|}
\hline \multirow{2}{*}{ No } & \multirow{3}{*}{ Norma } & Frekuensi & \multirow{2}{*}{ Kategori } \\
\cline { 3 - 4 } & & $\begin{array}{l}\text { Absolut } \\
\text { (FA) }\end{array}$ & Relatif (\%) & \\
\hline 1 & $0-6$ & 1 & $5 \%$ & Sangat Baik \\
\hline 2 & $7-12$ & 8 & $40 \%$ & Baik \\
\hline 3 & $13-18$ & 8 & $40 \%$ & Cukup \\
\hline 4 & $19-24$ & 3 & $15 \%$ & Kurang \\
\hline 5 & $25-30$ & 0 & $0 \%$ & Sangat Kurang \\
\hline Jumlah & 20 & $100 \%$ & \\
\hline
\end{tabular}

Berdasarkan tabel diatas dijelaskan bahwa, reaksi / reaction pemain Mahardika dengan kategori sangat baik ada 1 orang dengan rentangan nilai $0-6$. Kategori baik ada 8 orang dengan rentangan nilai 7-12. Kategori cukup ada 8 orang dengan rentangan nilai 13-18. Kategori kurang ada 3 orang dengan rentangan nilai 19-24. Kategori sangat kurang tidak ada.

\section{Teknik Dasar}

\section{a. Passing}

Tabel 4. 11 Distribusi Frekuensi passing

\begin{tabular}{|c|c|c|c|c|}
\hline \multirow[b]{2}{*}{ No } & \multirow[b]{2}{*}{ Nilai } & \multicolumn{2}{|c|}{ Frekuensi } & \multirow[b]{2}{*}{ Kategori } \\
\hline & & $\begin{array}{l}\text { Absolut } \\
\text { (FA) }\end{array}$ & $\begin{array}{l}\text { Relatif } \\
(\%)\end{array}$ & \\
\hline 1 & $9-10$ & 1 & $5 \%$ & Sangat Baik \\
\hline 2 & $7-8$ & 10 & $50 \%$ & Baik \\
\hline 3 & $5-6$ & 9 & $45 \%$ & Sedang \\
\hline 4 & $3-4$ & 0 & $0 \%$ & Kurang \\
\hline 5 & $0-2$ & 0 & $0 \%$ & Sangat Kurang \\
\hline \multicolumn{2}{|c|}{ Jumlah } & 20 & $100 \%$ & \\
\hline
\end{tabular}

Berdasarkan tabel diatas dijelaskan bahwa, Passing pemain Mahardika dengan kategori sangat baik ada 1 orang dengan rentangan nilai 9-10. Kategori baik ada 10 orang dengan rentangan nilai 7-8. Kategori sedang ada 9 orang dengan rentangan nilai 5-6. Kategori kurang tidak ada. Kategori sangat kurang tidak ada.

\section{b. Dribbling}

Tabel 4. 12 Distribusi Frekuensi Dribbling

\begin{tabular}{|l|l|l|l|l|}
\hline \multirow{2}{*}{ No } & \multirow{2}{*}{ Nilai } & \multicolumn{2}{|c|}{ Frekuensi } & \multirow{2}{*}{ Kategori } \\
\cline { 3 - 4 } & $16,99<$ & $\begin{array}{l}\text { Absolut } \\
(\text { FA) }\end{array}$ & $\begin{array}{l}\text { Relatif } \\
(\%)\end{array}$ & \\
\hline 1 & $17,00-19,00$ & 8 & $0 \%$ & Sangat Baik \\
\hline 2 & $19,01-21,00$ & 9 & $40 \%$ & Baik \\
\hline 3 & $21,01-23$ & 3 & $45 \%$ & Sedang \\
\hline 4 & $23>$ & 0 & $15 \%$ & Kurang \\
\hline 5 & Jumlah & 20 & $0 \%$ & Sangat Kurang \\
\hline \multicolumn{2}{|c|}{} & 0 & $100 \%$ & \\
\hline
\end{tabular}

Berdasarkan tabel diatas dijelaskan bahwa, dribbling pemain Mahardika dengan kategori sangat baik tidak ada. Kategori baik ada 8 orang dengan rentangan nilai 17,00-19,00 detik. Kategori sedang ada 9 orang dengan rentangan nilai 19,01-21,00 detik. Kategori kurang ada 3 orang dengan rentangan nilai 21,01-23 detik. Kategori sangat kurang tidak ada. 


\section{c. Shooting}

Hasil tes shooting ditampilkan dengan tabel sebagai berikut :

Tabel 4. 13 Distribusi Frekuensi Shooting

\begin{tabular}{|c|c|c|c|c|}
\hline \multirow{2}{*}{ No } & \multirow{2}{*}{ Nilai } & \multicolumn{2}{|c|}{ Frekuensi } & \multirow{2}{*}{ Kategori } \\
\cline { 3 - 4 } & $>17$ & Absolut (FA) & Relatif $(\%)$ & \\
\hline 1 & $12-16$ & 6 & $0 \%$ & Sangat Baik \\
\hline 2 & $8-11$ & 9 & $30 \%$ & Baik \\
\hline 3 & $4-7$ & 5 & $45 \%$ & Sedang \\
\hline 4 & $<3$ & 0 & $0 \%$ & Kurang \\
\hline 5 & Jumlah & 20 & $100 \%$ & \\
\hline \multicolumn{2}{r|}{} \\
\hline
\end{tabular}

Berdasarkan tabel diatas dijelaskan bahwa, shooting pemain Mahardika dengan kategori sangat baik tidak ada. Kategori baik ada 6 orang dengan rentangan nilai 12-16. Kategori sedang ada 9 orang dengan rentangan nilai 8-11. Kategori kurang ada 5 orang dengan rentangan nilai 4-7. Kategori sangat kurang tidak ada.

Tabel 4. 14 Frekuensi Kondisi Fisik Pemain Klub Mahardika

\begin{tabular}{|c|c|c|c|c|}
\hline Rumus & Interval & Kategori & Frekuensi & Frekuensi Relatif \\
\hline $\mathrm{X}>\mathrm{M}+1,5 \mathrm{~S}$ & $>12,59$ & Sangat Tinggi & 1 & $5 \%$ \\
\hline $\mathrm{M}+0,5 \mathrm{~S}<\mathrm{X} \leq \mathrm{M}+1,5 \mathrm{~S}$ & $10,57-12,59$ & Tinggi & 7 & $35 \%$ \\
\hline $\mathrm{M}-0,5 \mathrm{~S}<\mathrm{X} \leq \mathrm{M}+0,5 \mathrm{~S}$ & $8,55-10,57$ & Cukup & 6 & $30 \%$ \\
\hline $\mathrm{M}-1,5 \mathrm{~S}<\mathrm{X} \leq \mathrm{M}-0,5 \mathrm{~S}$ & $6,53-8,55$ & Rendah & 4 & $20 \%$ \\
\hline $\mathrm{X} \leq \mathrm{M}-1,5 \mathrm{~S}$ & $<6,53$ & Sangat Rendah & 2 & $10 \%$ \\
\hline \multicolumn{2}{|c|}{ Total } & & 20 & $100 \%$ \\
\hline
\end{tabular}

Tabel 4. 15 Distribusi Frekuensi Kondisi Teknik Dasar Pemain Klub Mahardika

\begin{tabular}{|c|c|c|c|c|}
\hline Rumus & Interval & Kategori & Frekuensi & Frekuensi Relatif \\
\hline $\mathrm{M}+1,5 \mathrm{~S}<\mathrm{X}$ & $>44,1$ & Sangat Tinggi & 1 & $5 \%$ \\
\hline $\mathrm{M}+0,5 \mathrm{~S}<\mathrm{X} \leq \mathrm{M}+1,5 \mathrm{~S}$ & $39,7-44,1$ & Tinggi & 9 & $45 \%$ \\
\hline $\mathrm{M}-0,5 \mathrm{~S}<\mathrm{X} \leq \mathrm{M}+0,5 \mathrm{~S}$ & $35,3-39,7$ & Cukup & 3 & $15 \%$ \\
\hline $\mathrm{M}-1,5 \mathrm{~S}<\mathrm{X} \leq \mathrm{M}-0,5 \mathrm{~S}$ & $30,9-35,3$ & Rendah & 6 & $30 \%$ \\
\hline $\mathrm{X} \leq \mathrm{M}-1,5 \mathrm{~S}$ & $<30,9$ & Sangat Rendah & 1 & $5 \%$ \\
\hline \multicolumn{2}{|c|}{ Total } & & 20 & $100 \%$ \\
\hline
\end{tabular}

\section{KESIMPULAN}

1. Kondisi fisik pemain sepak bola klub mahardika U-18 termasuk dalam kategori cukup, ini terbukti dengan hasil tes kondisi fisik terdapat 5\% (1 orang) yang termasuk dalam kategori sangat baik, 35\% (7 orang) dalam kategori baik, 30\% (6 orang) dalam kategori cukup, 20\% (4 orang) dalam kategori kurang dan $10 \%$ ( 2 orang) dalam kategori sangat kurang. Memperoleh rata-rata sebesar 9.50 dalam kategori cukup.

2. Kondisi teknik dasar pemain sepak bola klub mahardika U-18 termasuk dalam kategori cukup, terbukti dari hasil tes teknik dasar terdapat 5\% (1 orang) dalam kategori sangat baik, 45\% (9 orang) dalam kategori baik, 15\% (3 orang) dalam kategori sedang, 30\% (6 orang) dalam kategori kurang 
dan 5\% (1 orang) dalam kategori sangat kurang. Memperoleh rata-rata sebesar 37,50 dalam kategori cukup.

\section{DAFTAR PUSTAKA}

Adiatmika, I. P. G dan Santika, I. G. P. N. (2016).Tes dan Pengukuran Olahraga.Udayana University Press: Denpasar.

Agustina, R. S. (2020). Buku Jago Sepak Bola. Cemerlang: Tangerang Selatan.

Azidman, L., Arwin, dan Syafrial. (2017). "Profil Kondisi Fisik Pemain Sepak Bola Sma Negeri 1 Kaur".Jurnal Ilmiah Pendidikan Jasmani.1 (1) 35-39..

Bangun, S. Y. (2016). "Peran Pendidikan Jasmani Dan Olahraga Pada Lembaga Pendidikan Di Indonesia".Jurnal Publikasi Pendidikan. 3 (6) 156-167.

Depdiknas.(2000). Pedoman dan Modul Pelatihan Kesehatan Olahraga Bagi Pelatih Olahraga Pelajar.Jakarta.

Erlangga, S.Y. (2013). "Survei Kondisi Fisik Dan Keterampilan Teknik Dasar Sepak bola".Jurnal Kesehatan Olahraga. 1 (2) 1-6.

Honggowiyono, P. (2015). Pertumbuhan dan Perkembangan Peserta Didik Untuk Guru dan Calon Guru.Penerbit Gunung Samudera: Malang.

Ismaryati.(2008). Tes Pengukuran Olahraga. Surakarta: UPT Penerbit dan Percetakan UNS.

Scheunemann, dkk.(2013). Kurikulum dan Pedoman Dasar Sepak Bola Indonesia.PSSI.

Setiawan, D. (2013). "Kondisi Fisik Pemain Sepak bolaKlub Asyabab Di Kabupaten Sidoarjo". Jurnal pendidikan Olahraga.1 (1) 1-5.

Subagyo, I. (2010). Pedoman Pelaksanaan Pengembangan Tes Kecakapan "David Lee” untuk Sekolah Sepak bola (SSB) Kelompok Umur 14-15Tahun.Tesis. Yogyakarta: FIK UNY.

Sulasmono, R. (2016). "Analisis Deskriptif Kondisi Fisik Pemain Sepak bola SSB Tunas Jaya Sidoarjo".Jurnal Kesehatan Olahraga. 4 (3) 62-72.

Sulistiyono, NP. (2018). Kondisi fisik sepak bola. Yogyakarta.UNY Press 2018.

Sugiyono.(2018/2017).Metode penelitian kuantitatif, kualitatif, dan R\&D. Bandung:Alfabeta.

Sugiyono. (2019). Metode penelitian kuantitatif, kualitatif, dan R\&D. Bandung: Alfabeta. 